\title{
MELANCOLIAS ESPACIAIS EM “O SUICIDA” DE LOBIVAR MATOS
} SPATIAL MELANCHOLIES IN “O SUICIDA” FROM LOBIVAR MATOS
MELANCOLIAS ESPACIALES EN “EL SUICIDA” DE LOBIVAR MATOS

\author{
João Carlos Nunes Ibanhez \\ Mestre pelo Programa de Pós-Graduação em Geografia \\ Universidade Federal da Grande Dourados (UFGD) \\ zamoms@hotmail.com
}

Resumo: Trataremos nesse texto de uma única poesia intitulada "O suicida" de Lobivar Matos, compondo um quadro de ideias sobre sentidos espaciais. Esse valor numérico (uma - [1]), é a unidade máxima da poesia que se desdobra em 26 versos. "O suicida" revela o espaço Lobivariano na máxima do modernismo, sua estética adornada de um arranjo de beleza que paira no nível das Belas Artes e não esconde a podridão do mundo moderno, engolindo o "sujeito nômade" que tem sua trajetória iniciada em um ponto não que a "periférica regiáo global". Seu circuito geográfico vai culminar em um aprisionamento espacial, sua "cela" é o próprio mundo e as correntes que o aprisionam é a cidade nova, um ambiente superlotado de hostilidade. No vagar pelas ruas, ou na atmosfera fechada contra a externalidade, o ambiente envolvente em uma barganha recíproca com o indivíduo vai resultar em um espaço melancólico e desesperado. Em nossa análise, pretendemos dar cabo de responder duas questóes nucleares: Como pode o poema que trata tanto de traços íntimos e escalas externas, dialogar com a Geografia de cunho científico? Quais são as topografias adversas que levam o sujeito a renegar o espaço e consequentemente a vida?

Palavras-chave: Suicídio; Não-lugar; Topografias adversas; Poesia; Lobivar Matos

Abstract: We're considering this text from a single poetry, "O suicida" from Lobivar Matos,
composing a chart of ideas regarding spatial senses. This numeric value (one - [1]), is the
maximum unit of poetry which is unfolded in 26 verses. "O suicida" reveals the Lobivarian
space modernism principle, it's adorned aesthetic from a beauty arrange which hangs at Fine
Arts level is not able to hide the modern world's filthiness, swallowing the "nomad subject",
which has it's path initiated in a point which differs from the "peripheral global region". Its
geographic borders culminate in a spatial imprisonment; its "cage" becomes the world itself
and the chains which imprison him, a new city. An environment overflowed by hostility.
While wandering through the streets or away from external atmosphere; the surroundings
engaged into a reciprocal bargain with an individual which leads to a desperate and mel-
ancholic gap. We intend to answer those two core questions: How come a poem which
treats deeply intimal traces and external scales, could dialogue with a scientific purpose 
Geography? What are the adverse topographies that lead the subject to deny the space and consequently life itself?

Key-words: Suicide; Non-places; Adverse topographies; Poetry; Lobivar Matos

Resumen: Trataremos en ese texto de una sola poesía, "El suicida” de Lobivar Matos, componiendo un cuadro de ideas sobre sentidos espaciales. Este valor numérico (una - [1]), es la unidad máxima de la Poesía que se desdobla en 26 versos. "El suicida" revela el espacio Lobivariano en la máxima del modernismo, su estética adornada de un arreglo de belleza que bordea al nivel de las Bellas Artes y no esconde la podredumbre del mundo moderno, tragando el "sujeto nómada" que tiene su trayectoria iniciada en un punto no que la "periférica región global". Su circuito geográfico va a culminar en un encarcelamiento espacial, su "celda" es el propio mundo y las corrientes que lo aprisionan es la ciudad nueva, un ambiente superpoblado de hostilidad. En el vagar por las calles, o en la atmósfera cerrada contra la externalidad, el ambiente envolvente en una negociación recíproca con el individuo va a resultar en un espacio melancólico y desesperado. En nuestra análisis pretendemos dar respuesta a dos cuestiones nucleares: ¿Cómo puede el poema que trata tanto de trazos íntimos y escalas externas, puede dialogar con la Geografía de cuño científico? ¿Cuáles son las topografías adversas que llevan al sujeto a renegar el espacio y consecuentemente la vida?

Palabras-llave: Suicidio; No-lugar; Topografías adversas; Poesía; Lobivar Matos

\title{
INTRODUÇÁO
}

\begin{abstract}
"Que tipo de sociedade é esta, em que se encontra a mais profunda solidão no seio de tantos milhóes; em que se pode ser tomado por um desejo implacável de matar a si mesmo, sem que ninguém possa prevê-lo? Tal sociedade não é uma sociedade, ela é como diz Rousseau, uma selva habitada por feras selvagens." Karl Marx (Sobre o Suicídio, 2006, p. 28).
\end{abstract}

O "conjunto da obra" de muitos poetas, de diversas maneiras foi analisado pela Geografia ${ }^{1}$, onde a totalidade dos poemas ou os mais significativos que expressem a ideia central de um autor, alcançariam uma proximidade para com os conceitos trabalhados. No entanto, esse não é o nosso objetivo. Evocamos isso para dar uma dimensão da perspectiva do que desejamos por em xeque. O "conjunto da obra" não nos interessa aqui, é a unicidade do poema "O suicida" de Lobivar Matos o objetivo maior de nosso ponto de vista geográfico dialogando com a Arte.

O "conjunto da obra" de grandes cânones não só da poesia como da literatura em geral já foi alvo de interceptação geográfica. A título de exemplo citamos alguns: Machado de Assis (BARCELLOS, 2009); João Cabral de Melo Neto (FEITOSA; LIMA, 2013); (PINHEIRO NETO, 2012); Monteiro Lobato (GRACIOLI; PEZZATO, 2014); Clarice Lispector (SUZUKI, 2006); Carlos Drummond de Andrade (SILVA, 2014); Patativa do Assaré (SEEMANN, 2007); Ferreira Gullar (SANTOS; FEITOSA, 2013); Jorge Amado (ARAÚJO, 2007); (CASTRO, 2013); Ariano Suassuna (OLIVEIRA, 2008); José Saramago (PINTO, 2012); Italino Calvino (SILVA, 2004). 
O projeto poético de Lobivar Matos estampa um universo um tanto curioso e complexo; ele não é um grande cânone da Literatura e da Poesia brasileira, sendo um total desconhecido das grandes agências de publicidades e da crítica literária bem como da academia científica. Ele mesmo já declarou, ser um desconhecido por meio do eu lírico em um poema ${ }^{2}$. Se é assim, porque damos tanta atenção a esse poeta? De maneira bem específica, Lobivar Matos toca em assuntos que "talvez" a Geografia não tenha se debruçado.

Grandes literatos mundiais também se encaixam nesse "talvez", usando como laboratório as paisagens das cidades e dos lugares íntimos para compor suas obras artísticas: Allan Poe, Charles Baudelaire, Balzac e Dostoievski. É o mundo, o próprio laboratório dos escritores, eles transitam entre as multidóes, vasculham os bueiros, remexem a lama pisada pelos transeuntes, reviram as latas de lixo atrás do último "pé rapado" que ali procurou uma fruta podre, náo medindo esforços em busca sublime de um espaço que ofereça poética. $\mathrm{O}$ espaço parece ser o grande artifício para a poesia, no momento em que ela vasculha as sarjetas para se estruturar, vacinando-se contra uma parte da realidade oferecida, exaltando a fantasia e atingindo, assim, o espírito da arte. Pelos bueiros quentes e latas de lixos, a Poesia cria o seu próprio espaço, onde estáo contidas as interioridades dos sujeitos que as agenciam. É o espaço que está fora do âmbito de análises economicistas e geográficas.

Lobivar Matos, praticamente deslocado dos cânones da Literatura, póe o dedo na ferida da sociedade e joga aos ventos situaçóes encobertadas pela hipocrisia social, recriando um espaço inteiramente inventado a partir de sua fricção com o espaço real. No extremo oeste do país, a substancia prática e laboratório para sua poesia são os lugares periféricos e sujeitos marginais, tais como os mendigos, bêbados, imigrantes e outros excluídos. $\mathrm{O}$ lugar onde o poeta colhe e emite sua arte é por excelência fronteiriço, entre uma zona e um entorno. É nessa zona que o poeta acompanha um caso interessantíssimo que beira aqueles aforismos que pairam na sociedade: seria cômico se não fosse trágico. Ser imigrante e ter a perspectiva de apenas vender as forças de seus punhos como mão de obra barata para o mundo, são fatores que culminam em modelamentos espaciais do mundo moderno: aquele que não corresponde aos padrôes estipulados por uma determinada área, constará como segregado.

Entrar na poesia não é uma tarefa fácil, mas tentamos fazê-lo. As entradas são múltiplas, no entanto, decidimos não correr um risco muito grande e escolhemos as entradas que permitem que arrestemos uma máquina para o objetivo geográfico. O procedimento [método] é bem simplificado: penetramos o território da poesia e de lá saímos com exposiçôes espaciais. No tratamento que demos à obra lobivariana, direcionamos um olhar geográfico que promove sua contextualização conforme um trabalho maquinal, operando assim um desmonte na máquina literária do artista, para logo em seguida remontá-la com consideraçóes espaciais. Nesse "desmonte" que elaboramos junto à Literatura, nos referiremos a ela como máquina, à moda deleuze-guattarriana: "Cada segmento é uma

“[...] Eu sou poeta desconhecido, não sei o destino que me espera, porque sou o próprio destino" (MATOS, 1935, p. 11). 
máquina, ou uma peça de máquina, mas a máquina não é desmontada sem que cada uma de suas peças contíguas não constitua máquina por sua vez, tomando cada vez mais lugar” (DELEUZE; GUATARRI, 1977, p. 84).

É essa máquina que buscamos dialogar espacialmente, dando conta de desmontá-la e montá-la à nossa maneira geográfica. É uma empreitada ariscada, ainda sim foi o caminho que mais confortavelmente escolhemos para adentrar em território nebuloso. $\mathrm{O}$ mecânico que opera a máquina literária recobre uma realidade perversa. Diferente de outras correntes poéticas como o Romantismo, ${ }^{3}$ o eu íntimo é parte das transaçóes poéticas, para agenciar coletividades. Não estamos sugerindo que a produção artística exclui o ser íntimo do artista; estamos afirmando que é ele que catalisa as forças de percepçóes de conteúdos espaciais para promover e se conectar às coletividades e os casos políticos individuais que se ligam a um todo.

Para nosso ensaio, trazemos uma reduzida discussão sobre o suicídio e o espaço que não se molda ao sujeito e nem sujeito se acomoda ao espaço, náo lugar. Para isso, tentamos coligar fragmentos textuais de diferentes contextos, Não Lugares: Introdução a uma antropologia da supermodernidade, de Marc Augé e Sobre o suicídio de Karl Marx. Neste ligamento de textos, propomos um outro entendimento sobre não lugar.

O objetivo principal é de quebrar a ideia de que o não-lugaré somente um movimento da pós-modernidade, mas também da modernidade, talvez como categoria ela pertença. $\mathrm{Na}$ modernidade há traços de sujeitos que penetram e depois renegam o espaço na poesia no extremo do país bem antes dessa compartimentação temporal. Não estamos querendo instrumentalizar a Literatura para amparar ideias geográficas, mas dialogar e perceber outros movimentos espaciais no seio da poesia, que é o nosso parâmetro de análise.

\section{SUICÍDIO E NÁO LUGAR}

[...] Os não lugares criam tensão solitária

Marc Augé.

(Não lugar: introdução a uma antropologia da supermodernidade, 1994, p. 87).

Em "Sobre o suicídio", Marx, para compor sua obra, apoia-se em documentos escritos por Jaques Peuchet, um homem que navegou em vários setores da sociedade, como as Belas Artes, Administração, Medicina e foi estacionar nos departamentos de polícia da França. Peuchet deixou algumas consideraçóes a respeito das observaçóes que tirava no gabinete de polícia sobre o suicídio. Sáo, em grande parte, esses os dados que Marx usa para defender suas ideias.

$\mathrm{O}$ arquivista defende que o aumento de suicídios deve ser considerado um sintoma de uma má organização da sociedade, uma vez que em tempos de paralisaçóes, invernos

3 O aspecto mais marcante no Romantismo é a perspectiva de mundo centralizada no sujeito, ostentando dramas individuais por um espírito romântico. 
rigorosos e crises, os casos ocorrem, sendo um caráter epidêmico. Outros fatores, como más amizades, amores, doenças incuráveis, vida monótona levam "uma pessoa a livrar-se de uma existência detestável” (MARX, 2006, p. 24). Esse montante de causas que levam ao suicídio deveria ser catalogado como vertente de falhas da própria sociedade, "A classificação das diferentes causas do suicídio deveria ser classificação dos próprios defeitos da nossa sociedade" (MARX, 2006, p. 44).

O autor elenca numerosos casos de suicídios que emergem de relações entre as próprias pessoas. "Que outra coisa devemos esperar de três por centos de pessoas, que nem sequer suspeitam de que elas próprias, diariamente e a cada hora, pouco a pouco, assassinam sua natureza humana” (MARX, 2006, p. 43).

O não lugar é uma categoria criada para atender as novas concepções de relaçôes espaciais que se dão na pós-modernidade. Marc Auge invoca Michel de Certeau em seu texto para evidenciar o que esse autor pensava em relação a não lugar; "é para fazer alusão a uma espécie de qualidade negativa do lugar" (AUGÉ, 1994, p. 79). Os não lugares são assinalados pela negativação de identidade.

O não lugar é diametralmente oposto ao lar, à residência, ao espaço personalizado. É representado pelos espaços públicos de rápida circulação, como aeroportos, rodoviárias, estações de metrô, e pelos meios de transporte - mas também pelas grandes cadeias de hotéis e supermercados. [...] Se um lugar pode se definir como identitário, relacional e histórico, um espaço que não pode ser definir nem como identitário, nem como relacional, nem como histórico definirá um não lugar. A hipótese aqui defendida é a de que a supermodernidade é produtora de não lugares, isto é, de espaços que não são em si lugares antropológicos e que, contrariamente à modernidade baudelairiana, não integram os lugares antigos: estes, repertoriados, classificados e promovidos a "lugares de memória”, ocupam aí um lugar circunscrito e específico (AUGÉ, 1994, p. 73).

De forma bem generalizada, o não lugar é espaço entrecortado de circulação, de imagens, de movimento, de consumo, espaço de anonimato, uma oposição ao espaço da rotina e do cotidiano. Enquanto que o lugar se demonstra um espaço vazio, o não lugar é "recheado" de pluralidades. O primeiro denotaria um acorrentamento social, o segundo uma liberdade individual em meio à multidão (tensão solitária). A dicotomia é ainda maior, espaço reservado e de aconchego contra espaços públicos.

E qual é a "amarração" entre essas duas teorias bem distantes no espaço, no tempo e nas circunstâncias? Para o ligamento com a poesia, "anarquizamos" a noção de não lugar estamos defendendo a suspeita de uma rejeição de um sujeito a um determinado espaço. Não há como defender um território que não lhe pertence, também não há condições de se acomodar nesse território uma vez que não há identificação com o espaço. É justamente

Posso eu, sujeito analista de Poesia geograficamente, deturpar o conceito de uma categoria analisada minuciosamente por um grande teórico (Marc Augé), que tem por base uma orientação histórico-antropológica? Estaria eu reduzindo as concepçóes de tal categoria, transferindo um sentido inexistente nela, em favor de uma conexão poética geográfica? 
por isso que fazemos uma ligação um tanto perigosa, uma proposição ousada para subsidiar nosso diálogo com a poesia: se há uma negação do espaço, então, em certos casos, teremos algum índice de suicídio, o sujeito não se acomoda ao espaço, uma vez que o espaço não acolhe o sujeito.

\section{SOBRE LOBIVAR MATOS}

[...] foi um poeta de vanguarda a compor nosso período modernista; mas foi, sobretudo, um grande observador no vasto laboratório do mundo; suas consideraçóes acerca dos homens e de suas comunidades permanecem atemporais porque ainda revelam o desejo de opressão do ser humano para com seus pares.

Leoné Astride Barzotto,

[Batuque chiando no terreiro: a presença africana na literatura de Lobivar Matos, 2012, p. 238].

Lobivar Matos nasceu em Corumbá, cidade do extremo oeste do país e do estado de Mato Grosso do Sul no ano de 1915, com filiação de Manoel Augusto de Matos e Brasília Nunes de Matos. A infância é marcada pelas paisagens periféricas da cidade e pela beleza exuberante da planície alagada dessa peculiar região. Muda-se para o Rio de Janeiro e forma-se em Direito nos anos trinta, onde lança suas obras. Depois disso, passa a trabalhar por breves períodos em jornais como crítico, jornalista e cronista nas cidades de Campo Grande, Corumbá e Cuiabá. Morre em 27 de outubro de 1947 no Rio de Janeiro, precocemente aos trinta e dois anos, em decorrência de uma operação malsucedida, na tentativa de amenizar as dores de uma úlcera.

E qual é o teor poético singular em Lobivar Matos que nos convida para uma experiência espacial?

As obras de Lobivar Matos foram elaboradas na década de 1930, quando o antigo estado de Mato Grosso ainda não estava divido em norte e sul; ${ }^{5}$ o poeta é considerado o primeiro modernista dessas bandas. Sua primeira obra foi elaborada no ano de 1935 Areôtorare: Poemas boróros, editora Irmáos Pongetti. Nesta obra poetiza as relaçóes dos Boróros, ${ }^{6}$ as dimensóes da aldeia e o mundo moderno que a envolve. Na segunda obra, Sarobá: Poemas, lançada pela Minha Livraria Editora em 1936, o poeta verseja o cotidiano de um bairro negro de mesmo nome (Sarobá) que funciona em lógica própria; em vários momentos a poesia repousa nesse terreno, mas hora ou outra escapa para o seu entorno. "O suicida" é um dos vários poemas do livro.

Não há acumulação pessoal em Lobivar Matos. O sujeito íntimo surge como um catalisador para expulsar a angústia, o trágico e o cômico em seu olhar acumulativo. Suas

Não havia divisão entre norte e sul no estado de Mato Grosso na época de produção e lançamento das obras de Lobivar Matos. A divisão do estado acontece em 11 de outubro de 1977.

6 Decidimos manter o formato da grafia proposto pelo poeta, que tem acento agudo colocado no segundo "ó", mesmo que todos os documentos consultados tenham grafias excluindo esse acento. 
duas obras que formam uma unidade, repartida em dois grandes polos (dois blocos), funcionam no estado de esfacelamento, há uma fragmentação generalizada que caracteriza níveis de diferenciação. O espaço na experiência da escrita não é homogêneo; um espaço que se mostra movediço e complexo.

Atingir o plano global com pendências do lócus é uma constante em Lobivar Matos. Assuntos que tratam da morte em diferentes situaçóes são experimentadas na poesia. Essa que estamos aproximando junto a Geografia paira em vários âmbitos, desde sua desconhecida desterritorialização, quanto no canto mais íntimo possível, no quarto de um suicida.

\section{POESIA E ESPAÇO}

O anti-herói ${ }^{7}$ de Lobivar Matos é marcado por um movimento inverso ao biônimo territorialidade e desterritorialização, aqui ele primeiro desterritorializa de seu ambiente inicial, quebrando vínculos com o passado ${ }^{8}$, alcançando uma nova territorialidade, ou seja, reterritorialização. Nada sabemos de sua territorialização inicial, não há traços do seu passado espacial, sabemos sim de sua desterritorialização e de uma má sucedida reterritorialização.

Sua desterritorialização sendo uma marca rápida, vai culminar em um erro um tanto grave, já que o próximo ponto a ser reterritorializado parece dar poucas chances àqueles que vem de longe. Dizemos que é um erro, pois ele vai escolher logo a "periférica regiáo global" ", um lugar marcado tanto pelo apagamento/esquecimento cultural como socioeconômico.

$\mathrm{Na}$ nova territorialização de um novo espaço, a personagem vai perambular pela cidade em busca de trabalho e dignidade. É decepcionante, uma vez que através de um mapeamento corpóreo-presencial, confere todas as possibilidades e ofertas de emprego, mas parece não haver emprego justamente para um corpo estranho. Será que não há emprego para ninguém, ou somente para ele? Os padróes territoriais devem ser atendidos para aquele que almeja vender-se ao plano capitalista. A cidade, que é nova para o forasteiro, não o recebe bem, uma vez que ele também é novo para a cidade.

\footnotetext{
O Anti-heroi não é nem vilão nem herói, mas continua sendo protagonista.
}

No livro de Gabriel Garcia Marquez, Cem anos de Solidão (2014), as personagens só criam o vilarejo de Macondo, pois não há uma alternativa. "Na sua juventude, José Arcádio e seus homens, com mulheres e crianças e animais e todo tipos de utensílios domésticos, atravessaram a serra buscando uma saída para o mar, e ao cabo de vinte e seis meses desistiram da aventura e fundaram Macondo para não ter que empreender o caminho de volta. Era, pois, um caminho que não lhe interessava, porque só podia conduzir ao passado" (MARQUEZ, 2015, p. 52). O anti-herói de Lobivar Matos parece não querer dar meia volta e reterritorializar um lugar que já foi seu território, ele tem necessidade de descobrir outros territórios.

9 "Chupamos" a ideia de "periférica região global” do artigo "Lobivar Matos na Periférica Regiāo Global: Vida e Obra" de Paulo Sérgio Nolasco dos Santos onde ele afirma o seguinte: "Hoje, distanciados do tempo de Lobivar, podemos voltar o olhar para sua obra, na intenção não só de ressaltar a criatividade do poeta, já celebrada por alguns, mas sobretudo com o propósito de verificar o caráter especialmente vital, dialógico, que sua obra faz instigar na análise de uma região particularmente singular, na relação do local com o global, para onde está se direcionando, de modo especial, o olhar da crítica literária e cultural do continente latino-americano" (NOLASCO SANTOS, 2007, p .120). 
A vida moderna da industrializaçáo muda o ritmo de vida, aquele que for lento ou não se encaixar nos padrôes do novo território, vai perceber uma não solidariedade. $\mathrm{A}$ angústia do sujeito nômade é provocada pelo desamparo territorial. Nessa empreitada, para evidenciar espacialidades, a tática é a topografia que se inclina sobre a Literatura.

O poeta, em sua sublimação pura, $^{10}$ carrega espacialidades da margem de uma regiáo periférica, redundância espacial, "margem da margem". É nesse âmbito que o artista assiste a um caso particular que parece lhe chocar, pela comicidade de seu desfecho e pelo contexto que leva a um final trágico.

\section{O suicida}

Ele veio de longe...

Trazia uns niqueis no bolso

e uma grande ilusão dos homens.

Chegou aqui e andou pela cidade toda

procurando emprego.

Pediu de casa em casa

e ninguém tinha emprego para lhe dar.

Ontem, à tarde,

fechou-se no quarto,

escreveu uma porção de cartas;

deitou-se no jornal estendido no assoalho,

refletiu meia hora no que ia fazer

e achou que era o maior desgraçado do mundo

e que o único remédio

era acabar com aquela vida infame e miserável,

aquela vida de incerteza e de angústia

Depois, alucinado e delirante, o pobre diabo abriu a janela

e se esborrachou no chão.

Logo os jornais falaram

do ato tresloucado do rapaz.

Estamparam sua fotografia na primeira página.

Contaram lorotas sobre a vida do suicida

e aumentaram a tiragem

consideravelmente.

Entretanto,

o moço também batera às portas dos jornais.

(MATOS, 1936, p. 55-56).

10 Gaston Bachelard diz que a sublimação absoluta é a criação pura, a criação que não deve nada as paixôes e ao desejo, é essa a essência da poesia: "Mas nos parece que a poesia dá provas abundantes dessa sublimação absoluta" (1978, p. 191). Essa sublimação dificilmente vai ser cópia de uma realidade, mesmo que nela se escore, por isso cita a frase de um poeta: "Não há poesia, se não há absoluta criação" (BACHELARD, 1978, p. 193). 
Ali, no interior de um bairro segregado (Sarobá), juntam-se aos marginalizados, outros excluídos da sociedade, quem sabe pela ausência de uma opçáo de morada. A decadência atingi-os de forma arrasadora, uns parecem resistir muito bem, já outros não encaram da mesma forma. O restante da sociedade não dá crédito aos transeuntes, andarilhos, passageiros e provisórios e muito menos aos "diferentes". Tendem a repelir pessoas fora de um padrão estipulado, não há valorização do sujeito como indivíduo componente da sociedade. Esses que fogem à regra territorial, são ceifados pelo duro golpe do “não!". O suicida está nesse âmbito espacial emocional e mercadológico de competição.

A modernidade recolocou a espantosa cisão sujeito-objeto, transformando nosso corpo em uma embalagem da alma, do espírito, da psique e da matéria. Em certos momentos, somos interpelados como corpos; em outros, a partir de alguma transcendência da própria embalagem. Ora virtuosos, ora belos, o interior e o exterior sendo constantemente invocados desde diferentes espaços de discursividades, seja do social, seja do simbólico. De qualquer maneira, É nele - no corpo - e a partir dele que as discriminações ocorrem (BANDEIRA; BATISTA, 2002 pp. 134-135).

Esse raciocínio permeia a lógica do suicida. Por não se encaixar em alguns desses padróes que regem a nossa sociedade, o indivíduo é sufocado e rejeitado, o meio enxerga sobre eles apenas a capa corporal (embalagem da alma), deixando de visualizar a índole.

O fato é que milhares de sujeitos, em diversos espaços de nossas vidas, não suportam o preconceito, a marginalização e a exclusão, trocam de cidade ou estado e náo conseguem se dar muito bem, não se efetivam em um emprego formal. Pessoas são julgadas por seus trajes e pelas suas condutas. As características sociais do sujeito nômade da poesia têm complicadas negociaçóes com o espaço. Talvez uma Geografia social. Esse que veio de longe trazendo moedas no bolso e ilusões, depois de um caça ao "ganha pão", se desespera; quem não se frustraria? Começa a achar que ele é o errado (o maior desgraçado do mundo) nos espaços da lógica mercadológica, que é o mundo.

Esse sujeito parece responder à pergunta de Raul Seixas: "Por quê deixar que o mundo lhe acorrente os pés?" 11 Mesmo sendo transeunte, passageiro, o indivíduo parece estar encarcerado. É o repúdio à natureza do sistema capitalista, descortinando para nós dimensóes de espaço que atingem o universal, sendo o próprio mundo o espaço de uma prisão. $\mathrm{O}$ mundo, na lógica que se encontra, é uma prisáo. $\mathrm{O}$ sujeito compreendendo sua vida infame e miserável, achando-se o maior desgraçado dessa prisão, responde ao "Maluco Beleza", dando fim à sua própria vida, pulando do quarto e se esborrachando no chão, para assim deixar de ser acorrentando.

$11 \quad$ No disco de 1977, O dia em que a Terra Parou, Raul Seixas na música Você (7o faixa) nos comtempla com questionamentos que atingem o íntimo do sujeito: "Você alguma vez se perguntou por quê?? Faz sempre aquelas mesmas coisas sem gostar, mas você faz. Sem saber por que você faz e a vida é curta! Por quê deixar que o mundo lhe acorrente os pés. Finge que é normal estar insatisfeito. Será direito, o que você faz com você. Por quê você faz isso por quê?" (SEIXAS, 1977). 


\section{Figura 1 - "O Suicida"}

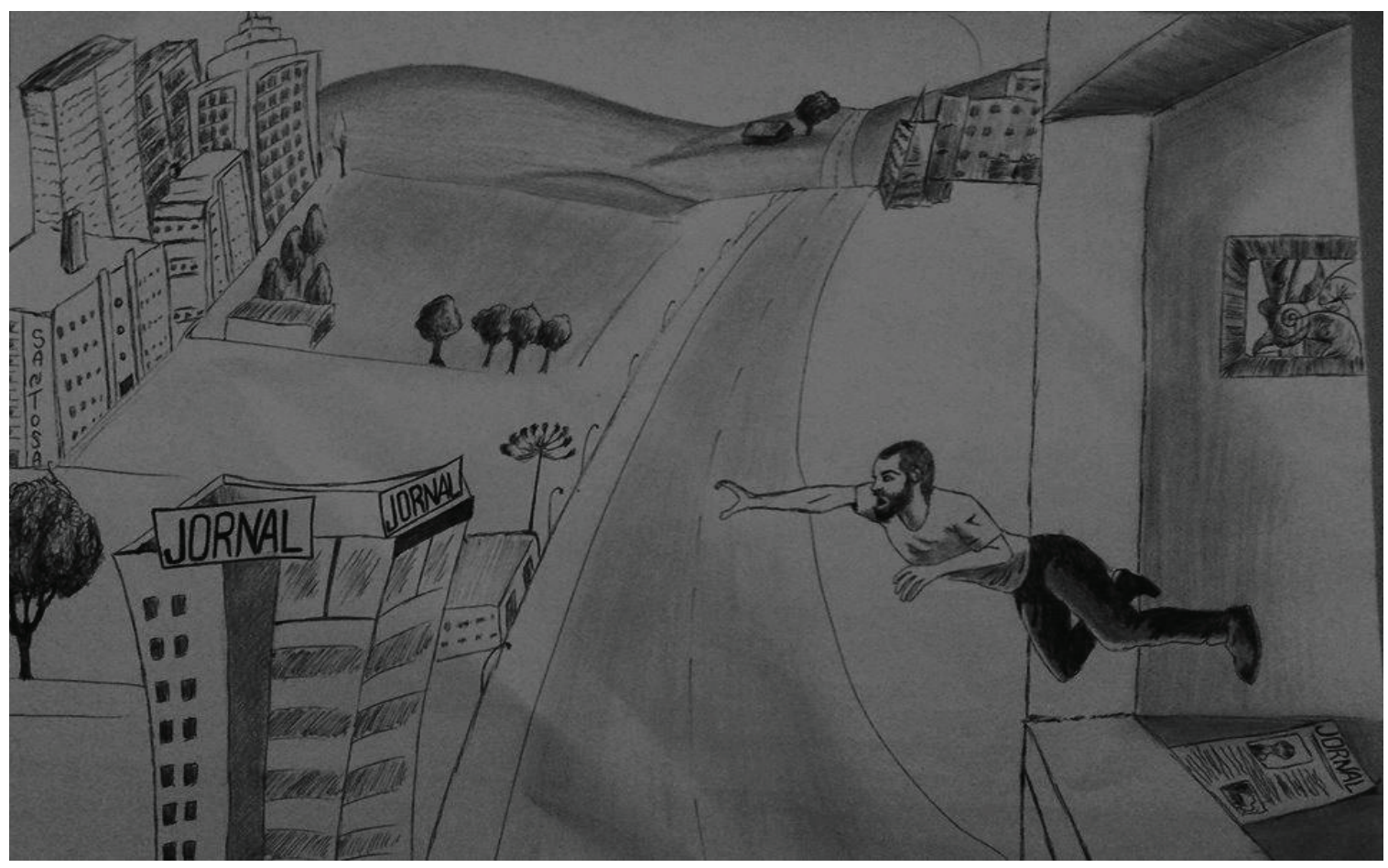

Autor: Luiz Gustavo da Penha Fontes dos Santos12

\section{TOPOGRAFIAS ADVERSAS}

\section{A queda}

Quantos sonhos em sonhos acordo aterrado

A terrores noturnos minha alma se leva

É um insight soturno é o futuro passando

$\mathrm{Na}$ velocidade terrível da queda

$\mathrm{Na}$ velocidade terrível da queda

Ante o colapso final a vertigem

próximo ao chão a penúltima descoberta

Que a lógica violenta das cores tinge

A velocidade terrível da queda

A velocidade terrível da queda

Como cair do céu é tão simples

Queda que a tudo e a todos transtorna

12 Decidimos para esse ensaio encomendar um desenho com o amigo Luiz Gustavo da Penha Santos Fontes. O método para composiçáo do desenho foi simples, lemos a poesia e construímos a representaçáo dela em um único momento e em uma única imagem. Agradeço ao amigo sua colaboração em meu programa. 
Ah! as bombas, a chuva, os anjos e seus loucos

O mundo todo na velocidade terrível da queda

O mundo todo na velocidade terrível da queda

Resvalando em abismos um pôr do sol furioso

Que a sensação de perda ao ver exagera

É o desespero vermelho de um apocalipse luminoso

Ejaculado da velocidade terrível da queda

Ejaculado da velocidade terrível da queda

Diante do medo um sorriso aeróbico

Nas bochechas a câimbra de uma alegria incompleta

Nada como um sorriso burro e paranoico

Para não perceber a velocidade terrível da queda

Para não perceber a velocidade terrível da queda Lobão ${ }^{13}$

(A queda, Nostalgia da Modernidade,1995)

O suicida não servia como peça de engrenagem para o sistema, por não corroborar com os padróes estipulados pelas casas/estabelecimentos nos quais pediu emprego, nem mesmo pela agência de publicidade. No entanto, ele serviu como clientela, ele compra o jornal para procurar emprego. Depois busca emprego no próprio jornal. Ironicamente ele vira substância do jornal com seu próprio suicídio. Há um circuito geográfico que o nômade percorre culminando e ultrapassando a morte.

O primeiro espaço da poesia circula nos ligamentos territoriais entre o longe, de onde ele veio, até atingir o "aqui". O ser narrativo da poesia está em seu território e narra um sujeito que interfere no espaço, “[...] o poeta desconhecido percorrerá muitos caminhos, e na condição de 'flauner', atravessando a cidade para poder experimentá-la, o errante poeta passará por lugares reais e imaginários, transposto pela capacidade criadora" (ARAUJO, 2009, p. 67). Para o sujeito observado da poesia, esses pontos territoriais (longe/aqui) constituem um espaço transicional temporal, ligamento com o passado. Esse espaço só acontece até certo momento, sua duração só vai até onde ele trazia a ilusão dos homens. Quantos sonhos em sonhos acordam aterrados?

O espaço sequencial é do estacionamento do novo território "chegou aqui". É a partir daí que se efetiva um espaço de descobrimento de ambos os lados, tanto do território que agora é penetrado, quanto do sujeito penetrante. Espaço de descoberta recíproca. Espaço de circulação interna, tráfego pela "cidade toda". Nessa circulação interna pela cidade, por todos os cantos (espaços), confere as oportunidades, mas não se dá bem. Pede emprego de casa em casa e só recebe respostas negativas. Espaço do estranhamento. A terrores

13 Gostaríamos de deixar claro que não concordamos com os ideais políticos do Lobão. No entanto, sua arte é bela em sentidos estéticos. Conseguimos neste ensaio criar ligamentos poéticos e espaciais entre "A queda" e o "O suicida”. 
noturnos a sua alma se leva. Há um mapeamento presencial feito pelo sujeito nômade, em vários pontos da cidade. Até um certo momento, seu corpo ainda náo repousou em um abrigo estável, há muita movimentação e trajeto corporal.

Há que se destacar o setor temporal, que se demonstra complexo, com início do segundo bloco poético (estrofe), interferindo no setor espacial, já que o espaço é do passado, "ontem à tarde". Então, o espaço inicial, desde sua desterritorialização até ele subir para o quarto e enfrentar a queda, é do passado, um espaço que náo existe mais. É o futuro passando.

O corpo precisa repousar e vai adentrar a um quarto que fica no alto, no mínimo no segundo andar, alugado com suas únicas moedas. Espaço de repouso. Ele repousa para refletir sobre sua vida e fecha-se na solidão. O quarto é a sua saída, sua fuga, mas também é solidão: "A seus abrigos de solidão se associam ao quarto [...]" (BACHELARD, 1978, p. 206). O sujeito cerra o espaço em si mesmo, "fechou-se no quarto". O abrigo é o assoalho, o chão, coberto com o jornal que já foi útil, leu os classificados e as ofertas de emprego. É um insight soturno: o chão parece ser o motor de escape, sua linha de fuga. O quarto é só um vetor de proteção, sua verdadeira linha de fuga é o chão, é ele que o protege. O chão é o espaço que minimante estabiliza nesse momento, mas infelizmente ele é falso, assoalho. Espaço de uma falsa proteção. O quarto é ambiente para outros espaços.

$\mathrm{O}$ sujeito da poesia reflete o que vai fazer, são trinta minutos que o tempo congela o espaço. Um espaço de análise e avaliação da interioridade. Mesmo que na menoridade do quarto e do chão, constituindo um espaço da intimidade, na sequência, o espaço é alavancado para uma maioridade absoluta: o plano universal, o maior desgraçado do mundo. O "ali" do ambiente do quarto (lócus), de alguma forma se liga ao restante do globo terrestre. Espaço melancólico. Uma imensidão intima ${ }^{14}$, o humano atinge o espaço global.

Depois de atingir escalas universais, o espaço é reduzido a uma decisão, uma remediação, acelerar o "mal irremediável": acabar com as incertezas da vida, a angústia e a miséria. Espaço de determinação. É na subsequência, que o espaço fica caótico, espaço de alucinação e delírio, que vai culminar na abertura para o espaço da exterioridade; uma fronteira entre a intimidade e a externalidade, onde a vista o desespero vermelho de um apocalipse luminoso. Não pode mais haver intimidade, nem o assoalho. Há uma decisão para descer até a uma topografia sólida, não há mais porque se esconder e se abrigar no espaço do chão falso, coberto pelo jornal. A topografia que resolve seus problemas é o chão concreto, é o que estabiliza definitivamente. Espaço da penúltima descoberta: queda que a tudo e a todos transtorna. $\mathrm{O}$ espaço paira no passado, no final da tarde onde resvala em abismos um pôr do sol furioso. É aí que há uma busca por um espaço de estabilização, o chão concreto vai denotar isso, já que cair do céu é tão simples. Diante do medo, num horizonte trêmulo, o pobre diabo delirante com um sorriso aeróbico e suas bochechas com a câimbra de uma alegria incompleta, é ejaculado

14 Bachelard (2008), analisando $A$ imensidão intima, diz que a grandeza e a imensidão estão em nós, um movimento do homem imóvel. 
na velocidade terrível da queda. Espaço de corpo esborrachado no chão. Espaço do suicídio. Espaço da morte. Espaço trágico.

O espaço em vida é encerrado. Houve uma renegação a todos os espaços anteriores, não lugar. Agora o espaço da morte vai culminar em divulgaçóes em outros espaços, de atos tresloucados e de lorotas, espaço "virtual", onde se aumenta a tiragem consideravelmente (reportagem/crônica/manchete). Agora em morte, o sujeito deixa de ser transeunte em vias de anonimato, para explodir em choque em furo jornalístico pairando em todos os espaços que a notícia flutua, sendo estampada a sua foto.

O último bloco poético, com dois versos, fecha o ciclo e cria ligamentos, tanto espaciais como temporais. O espaço da morte entra em choque temporalmente com o espaço da vida, espaço que foi de trajetórias, encontros e descontinuidades. $\mathrm{O}$ mesmo jornal que anuncia a morte, aumentado a tiragem, renegou o sujeito nômade impedido a penetração, a criação de laços espaciais e trabalhistas e agora promove manchetes em cima do corpo estranho que subjugou. Espaço que ficou fixado no passado, porque ele batera às portas dos jornais. Espaço cômico.

\section{CONSIDERAÇÓES MAQUINAIS}

O propósito deste texto foi trazer a possibilidade de diálogo com uma única poesia de Lobivar Matos, poeta que tem sua máquina literária referenciada nas estruturas marginais, locais de seu laboratório de análise da comédia dramática da vida. A unidade poética, "O suicida”, traça um curso geográfico iniciado em um ponto desconhecido, atravessando espaços públicos até culminar no aprisionamento social do sujeito. O quarto é ambiente que agencia sequências de múltiplos espaços.

Em primeiro momento fizemos uma modesta discussão sobre suicido e não lugar, utilizando textos de Karl Marx e de Marc Augé. Remexendo na conceituação de não lugar para adequar aos nossos propósitos, a nossa argumentação é de que a negação do espaço culminará em seu esfacelamento, levando o sujeito a dar cabo da sua própria existência.

Com vinte seis versos, "O Suicida" sinaliza uma estética adornada de uma comicidade, não tendo desejo de esconder a podridão do mundo moderno. O sujeito tem seu itinerário iniciado em um ponto que não é a "periférica região global", nada se sabe de sua territorializaçáo, nada se sabe do seu passado. Em busca pela sobrevivência, o sujeito da poesia vai percorrer uma rota geográfica resultando em auto aprisionamento, a "cela" é o próprio mundo, as correntes que o aprisionam são a cidade nova que recebe mal o corpo estranho. O sujeito vaga pelas ruas, de casa em casa em busca de emprego, mas ninguém tinha emprego a lhe dar. $\mathrm{O}$ espaço cria uma negativação para cima do corpo, vai se efetivando um espaço de hostilidade. É aí, que a linha de fuga é atmosfera fechada contra a externalidade, resultando em um espaço melancólico e desesperado.

A nossa análise conseguiu identificar escalas que variam desde traços íntimos até atingir o universal, imensidão intima. Conseguimos conectar um diálogo entre a Geografia e a poesia apontando as topografias adversas, que de maneira ou outra criaram um campo de força invisível, impedindo o sujeito de penetrar "socialmente" no espaço. Ele renega esse 
espaço e os anteriores ao seu passado e consequentemente renega a própria vida, indo de encontro com o espaço de estabilização, o chão. O circuito geográfico é encerrado definitivamente, desterritorialização da vida para reterritorializar no além-desconhecido.

O jornal aparece em três momentos: quando o sujeito vai pedir emprego; é usado para deitar no assoalho e depois, quando anuncia o suicídio. No final da poesia o jornal já não é apenas um objeto do espaço ou um lugar físico, agora é um agenciador que divulga e recria o espaço da morte. A poesia deixa estampado um espaço mesclado: o sujeito procurou emprego no jornal que anuncia o seu suicídio. Espaço mescla entre trágico e cômico, seria engraçado se não fosse triste.

Nosso texto foi elaborado em forma de ensaio, a nossa máquina desmontando a máquina literária de Lobivar Matos e remontando à nossa maneira geográfica com um discurso "talvez" perturbador, já que a escrita (linguajar) é "solta", numa quebra da rigidez científica; isso dá certo conforto com as palavras. Suavizamos as palavras, porque seguimos o conselho de Marc Brosseau (2007), geógrafo canadense, perito nesse trabalho que fazemos, Geografia + Literatura: essa aproximação entres esses campos distintos do saber, é também uma reflexão do modo (estilo) como compomos (escrevemos) a própria Geografia. 


\section{REFERÊNCIAS BIBLIOGRÁFICAS}

ARAÚJO, Heloisa Araújo. Geografia e Literatura: Um elo entre o presente e o passado no Pelourinho. 2007. Dissertação (Mestrado em Geografia) Instituto de Geociências, Universidade Federal da Bahia, Salvador, 2007.

AUGÉ, Augé, Não Lugares: Introdução a uma antropologia da supermodernidade. Papirus Editora, Campinas - SP, 1994.

BACHELARD, Gaston. Coleção Os pensadores. São Paulo: Abril Cultural, 1978.

BANDEIRA, Lourdes; BATISTA, Analía Soria. Preconceito e discriminação como expressóes de violência. Estudos Feministas, v.10, n.1, pp. 119-141. 2002.

BARCELLOS, FREDERICO ROZA. Espaço, lugar e literatura - o olhar geográfico machadiano sobre a cidade do rio de Janeiro. Espaço e Cultura, n. 25, pp. 41-52, 2009.

BARZOTTO, Leoné Astride. Batuque chiando no terreiro: a presença africana na literatura de Lobivar Matos. Polifonia, v.19, n. 26, pp. 235-248, 2012.

BROSSEAU, Marc. O Romance: outro sujeito para a Geografia. IN: CORRÊA, Roberto Lobato; ROSENDAHL, Zeny (org.). Literatura, Música e Espaço. Rio de Janeiro: EDUERJ, 2007.

CASTRO, Fátima Velez de. As paisagens literárias na obra de Jorge Amado: Navegando $\operatorname{com}($ o) turcos à descoberta da América. Soc. \& Nat., n. 25, pp. 229-238, 2013.

DELEUZE, Gilles e GUATTARI, Félix. Kafka: por uma literatura menor. Rio de Janeiro: Imago editora, 1977.

FEITOSA, Manir Miguel; LIMA, Renata Ribeiro. A Paisagem Cultural em João Cabral de Melo Neto: as vivências do Capibaribe. Linha d’Água, n. 26, pp. 51-66, 2013.

GRACIOLI, Filipe Rafael; PEZZATO, João Pedro. Orientação espacial e a Geografia de Dona Benta: observaçóes pela experiência vivido. Antares: Letras e Humanidades, v.6, n.11, 2014.

LOBÃO, João Luiz Woerdenbag Filho. A queda. Nostalgia da Modernidade. Gravadora Virgin, 1995.

MARQUEZ, Gabriel Garcia. Cem anos de Solidão. Tradução Eric Nepomuceno. 83 ed. Rio de Janeiro: Record, 2014.

MARX, Karl. Sobre o suicídio. São Paulo: Boitempo, 2006.

MATOS, Lobivar. Areôtorare: poemas boróros. Rio de Janeiro: Irmãos Pongetti, 1935.

Sarobá: poemas. Rio de Janeiro: Minha Livraria Editora, 1936.

OLIVEIRA, Natallye Lopes Santos. Representação Espacial de Nordeste: O olhar armorial de Ariano Suassuna. Dissertação (Mestrado em Geografia) - Universidade Federal Fluminense, Niterói, 2008. 
PINHEIRO NETO, José Elias. Geografia e Literatura: a paisagem geográfica e ficcional em Morte e Vida Severina de Joáo Cabral de Melo Neto. Boletim Campineiro de Geografia, v.2, n. 2, pp. 322-340, 2012.

PINTO, Flávia Alexandra Pereira. Espaço e Identidade: a percepção da paisagem na produção literária de José Saramago, Dissertação (mestrado interdisciplinar Cultura e Sociedade). Universidade Federal do Maranhão, São Luiz, 2012.

SANTOS, Alessandro Barnabé Ferreira; FEITOSA, Márcia Manir Miguel. Espaço E Memória: Poema sujo à luz da percepção da paisagem. Cad. Pesq., v. 20, n. 2, 2013.

SEEMANN, Jörn. Geografia, geograficidade e a poética do espaço: Patativa do Assaré e as paisagens da regiấo do Cariri (Ceará). Ateliê Geográfico, v.1, n.1 pp. 50-73, 2007.

SEIXAS, Raul. Você. O dia em que a Terra parou. Gravadora WEA, 1977.

SILVA, Felipe Cabañas da. Geograifa e lirismo social em "Sentimento do mundo", de Carlos Drummond de Andrade. Geograficidade, v.4, n.2, 2014.

SILVA, Janaina de Alencar Mota. Literatura e Cidade: Uma leitura geográfica da obra de Italo Calvino. Trabalho de conclusáo de curso (Bacharelado em Geografia) - Departamento de Geociências, Universidade Estadual de Londrina, Londrina, 2004.

SUZUKI, Júlio César. O Espaço na Narrativa: Uma leitura do conto "Preciosidade". Revista do Departamento de Geografia, n.19, pp. 54-67, 2006.

Recebido em junho de 2017. Aprovado em dezembro de 2017. 